\title{
Exposure to family violence from childhood to adulthood
}

\author{
Margot Shields', Lil Tonmyr ${ }^{1 *}$ (D, Wendy E. Hovdestad', Andrea Gonzalez ${ }^{2}$ and Harriet MacMillan ${ }^{2,3}$
}

\begin{abstract}
Background: Both childhood maltreatment (CM) and intimate partner violence (IPV) are public health problems that have been related to a wide range of adverse health consequences. However, studies examining associations between specific types of CM and experiencing IPV in adulthood have yielded conflicting results.

Methods: Using data from 10,608 men and 11,458 women aged 18 or older from Canada's 2014 General Social Survey, we examined associations between three types of CM—childhood physical abuse (CPA), childhood sexual abuse (CSA), and childhood exposure to IPV — and subsequent intimate partner violence (IPV) in adulthood (physical, sexual or emotional).

Results: When potential confounders were controlled, CPA, CSA and childhood exposure to IPV were associated with IPV in adulthood for both sexes (odds ratios, 1.7, 1.8 and 2.0 for men, and 2.2, 2.0 and 2.1 for women). When severity and frequency of CM were examined, a dose-response relationship between all three types of CM and IPV in adulthood was observed among women (meaning that as the severity/frequency of CM increased, the likelihood of reporting IPV also increased); among men, a dose-response relationship was observed only for CPA.

Conclusions: The association between CM and IPV in adulthood is particularly concerning because experiencing multiple forms of trauma has cumulative effects. Lifespan studies have shown that individuals who experience multiple incidents of abuse exhibit the highest levels of impairment. This underscores the importance of programs to eradicate both CM and IPV. This underscores the importance of programs to eradicate both CM and IPV. Future research should focus on assessing interventions designed to promote healthy relationships and the provision of emotional support and coping mechanisms to children and families in abusive situations.
\end{abstract}

Keywords: Intimate partner violence, Physical abuse, Sexual abuse, Childhood exposure to intimate partner violence, Domestic violence

\section{Background}

The World Health Organization defines intimate partner violence (IPV) as any "behaviour by an intimate partner that causes physical, sexual or psychological harm, including acts of physical aggression, sexual coercion, psychological abuse and controlling behaviours. This definition covers violence by both current and former spouses and other intimate partners" [1]. IPV victimization is

\footnotetext{
* Correspondence: Lil.Tonmyr@canada.ca

'Public Health Agency of Canada, 785 Carling Ave. 7th floor, Ottawa, ON K1A OK9, Canada

Full list of author information is available at the end of the article
}

associated with short- and long-term health consequences including injury and other physical health conditions, mental health symptoms and disorders, and death [2]. Those experiencing IPV use proportionately more health care services (primary care, emergency, and hospital), even when confounding factors such as socioeconomic status are taken into account [2].

The causes of IPV are complex. The ecological model contends the multiple risk factors are involved including individual, relationship, community, and societal factors [2-4]. An extensive body of literature has examined childhood maltreatment $(\mathrm{CM})$ as a risk factor for being

C The Author(s). 2020 Open Access This article is licensed under a Creative Commons Attribution 4.0 International License, which permits use, sharing, adaptation, distribution and reproduction in any medium or format, as long as you give appropriate credit to the original author(s) and the source, provide a link to the Creative Commons licence, and indicate if changes were made. The images or other third party material in this article are included in the article's Creative Commons licence, unless indicated otherwise in a credit line to the material. If material is not included in the article's Creative Commons licence and your intended use is not permitted by statutory regulation or exceeds the permitted use, you will need to obtain permission directly from the copyright holder. To view a copy of this licence, visit http://creativecommons.org/licenses/by/4.0/. The Creative Commons Public Domain Dedication waiver (http://creativecommons.org/publicdomain/zero/1.0/) applies to the data made available in this article, unless otherwise stated in a credit line to the data. 
victimized by IPV in adulthood, with the majority of studies focusing on associations with childhood sexual abuse (CSA) [5-18] and childhood physical abuse (CPA) $[5-7,9,10,12-22]$. Studies of associations with other types of CM, such as childhood exposure to IPV, emotional abuse, and neglect, are less common $[5,6,13-20$, 22-25]. Many of these studies have samples comprised exclusively of women $[5,9,10,13,14,17,19,20]$.

However, findings tend to be inconsistent. Some studies have found that $\mathrm{CM}$ increases the likelihood of IPV in adulthood; others have reported null associations between specific types of CM and IPV [5-7, $12-14,19,20,22,24,26-29]$. Two meta-analyses [30, 31] of associations between specific types of CM (CPA, CSA, childhood exposure to IPV, neglect, and emotional abuse) and IPV in adulthood concluded that associations were weak, but statistically significant. One of these studies [30] focused on associations between CM and IPV among men and noted a need for research on different kinds of $\mathrm{CM}$ and the co-occurrence of $\mathrm{CM}$ in relation to IPV victimization and perpetration among men.

Evidence is also mixed about whether greater severity of CM heightens the risk of IPV in adulthood $[5,9,12,15$, 18-20, 28, 32]. It has been argued that simply being exposed to CM, regardless of severity, increases the risk for future abuse [33]. Some studies have suggested that the number of types of maltreatment that a child experiences is more important in predicting IPV in adulthood than is the severity of a specific form of maltreatment $[15,34]$.

A Canadian study using data from the populationbased 1999 General Social Survey (GSS) found an association between CSA and IPV in adulthood for both sexes, although the relationship was weaker for men [11]. The 1999 GSS identified CSA and CPA with questions about life-time history of sexual and physical assault and age of onset; respondents reporting assault before age 18 were classified as having experienced CSA/CPA [35]. For the 2014 GSS, the questions were broadened to include items to measure CSA, CPA, and childhood exposure to IPV [36]. An analysis of 2014 GSS data observed an association between CSA/CPA and severe IPV in adulthood (being beaten, choked, threatened with a gun or a knife, or forced or manipulated into unwanted sexual activity) [37]. However, this study did not examine if increases in severity of CM augmented the likelihood of adult IPV victimization. Childhood exposure to IPV was not considered nor were sex differences in associations between CM and IPV victimization in adulthood.

This article uses data from the 2014 GSS to meet three objectives:

1. to examine associations between three types of $\mathrm{CM}$ (CPA, CSA, and childhood exposure to IPV) and being victimized by three types of IPV in adulthood (physical, sexual and emotional);

2. to investigate whether greater severity and frequency of specific forms of $\mathrm{CM}$ and the cooccurrence of different types of CM increase the risk of IPV in adulthood; and

3. to determine if associations between CM and IPV in adulthood differ by sex.

Examining these questions will address important gaps in the literature; associations between $\mathrm{CM}$ and IPV have rarely been examined among men and more studies are needed to clarify if the co-occurrence and severity of particular types of CM increases the likelihood of IPV.

In this article we use the terms "experienced" IPV or "reported IPV" to refer to "being victimized" by IPV. The article does not address IPV perpetration (see Limitations).

\section{Methods \\ Data source}

Data are from Statistics Canada's 2014 General Social Survey: Victimization. The GSS target population was household residents aged 15 or older living in the 10 provinces and 3 territories. Two samples were selected (one for the provinces; one for the territories) using complex multistage sampling designs that utilized a sampling frame derived from the census and various administrative sources, which combined landline and cellular telephone numbers. More information about the sample design is available in the GSS Microdata User Guide [38]. The response rate was $52.9 \%$ for the provinces (33,127 respondents) and $58.7 \%$ for the territories (2040 respondents). The two samples were pooled to produce estimates for all Canadians.

The study population for the present analysis was respondents aged 18 or older currently living with a spouse/partner or who had contact with an ex-spouse/ ex-partner in the past 5 years $(10,608$ men and 11,458 women). Respondents aged 15 to 17 years were excluded since our objective was to examine $\mathrm{CM}$ in relation to IPV in adulthood.

\section{Measures}

\section{Child maltreatment}

CPA, CSA, and childhood exposure to IPV were assessed retrospectively by asking respondents about "events that may have happened before you were 15" using the items in Fig. 1 (adapted from Shields et al., [39]).

The items for CPA and childhood exposure to IPV are from the Childhood Experiences of Violence Questionnaire (CEVQ) [40]. For each type of abuse, binary 


\section{CPA}

i) Before age 15 , how many times did an adult slap you on the face, head or ears, or hit you with something hard to hurt you? By adult, I mean anyone 18 years and over. (Exclude spanking)

ii) Before age 15, how many times did an adult push, grab, shove or throw something at you to hurt you?

iii) Before age 15, how many times did an adult kick, bite, punch, choke, burn you, or physically attack you in some way?

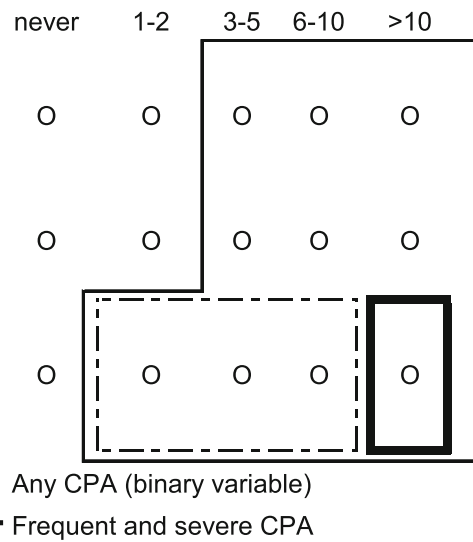

i) Before age 15, how many times did an adult force you or attempt to force you into any unwanted sexual activity, by threatening you, holding you down or hurting you in some way?

ii) Before age 15, how many times did an adult touch you against your will in any sexual way? By this, I mean anything from unwanted touching or grabbing, to kissing or fondling.
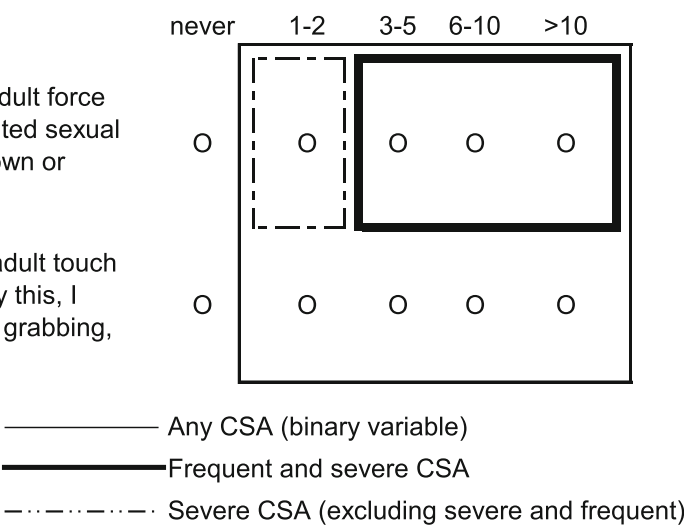

CEIPV

never $\quad 1-2 \quad 3-5 \quad 6-10 \quad>10$

i) Before age 15, how many times did you see or hear any one of your parents, step-parents or guardians hit each other or another adult?

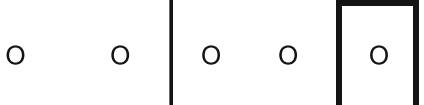

Any CEIPV (binary variable)

Frequent CEIPV

$\mathrm{CPA}=$ Childhood physical abuse

CSA $=$ Childhood sexual abuse

CEIPV=Childhood exposure to intimate partner violence

Note: Figure 1 is adapted from Shields et al, 2016 [39].

Fig. 1 Childhood maltreatment items and definitions. CPA = Childhood physical abuse. CSA = Childhood sexual abuse. CEIPV=Childhood exposure to intimate partner violence. Note: Fig. 1 is adapted from Shields et al., [39]

variables (yes/no) were created following CEVQ guidelines. As well, variables were derived to indicate the severity and frequency of abuse (Fig. 1). We also examined the co-occurrence of the three types of $\mathrm{CM}$ maltreatment as well as each type of CM occurring in isolation. We created a variable to indicate:

- no CM,

- CPA only (no CSA/childhood exposure to IPV),

- CSA only (no CPA/childhood exposure to IPV),
- childhood exposure to IPV only (no CPA/CSA),

- 2 or more types of CM.

We attempted to consider two co-occurrence categories separately (i.e., 2 types and 3 types) but there was insufficient sample size to consider 3 types.

For CPA and CSA, all incidents of abuse were included regardless of the relationship of the perpetrator to the child (e.g., parent, stepparent, other family member, teacher, stranger etc.). 


\section{Intimate partner violence in adulthood}

To identify physical, sexual and emotional IPV in adulthood, questions were asked about the respondent's current spouse/partner, and then, about the respondent's ex-spouse/ex-partner (if applicable and if they had contact in the past 5 years). Respondents in same-sex relationships are included in the study. IPV that occurred in dating relationships was excluded. The IPV items are based on the Conflict Tactics Scales [41, 42]. Questions about physical and sexual IPV pertained to experiences that occurred over the past 5 years; no time frame was specified for emotional IPV. Table 1 displays the items used to measure IPV.

\section{Covariates}

Selection of potential confounders to use in the multivariate regression models was based on a review of the

Table 1 Intimate partner violence (IPV) items and definitions

Physical IPV: reporting at least one of the following 9 experiences
During the past 5 years, has your spouse/partner or ex-spouse/ex-
partner:
1 threatened to hit you with his/her fist or anything else that could
have hurt you?
2 thrown anything at you that could have hurt you?
3 pushed, grabbed or shoved you in a way that could have hurt you?
4 slapped you?
5 kicked you, bit you, or hit you with his/her fist?
6 hit you with something that could have hurt you?
7 beaten you?
8 choked you?
9 used or threatened to use a gun or knife on you?

Sexual IPV: reporting at least one of the following 2 experiences

During the past 5 years, has your spouse/partner or ex-spouse/expartner:

1 forced you into any unwanted sexual activity, by threatening you, holding you down, or hurting you in some way?

2 subjected you to a sexual activity to which you were not able to consent. By this I mean were you drugged, intoxicated, manipulated or forced in other ways than physically?

Emotional IPV: reporting at least one of the following 7 experiences

Your spouse/partner or ex-spouse/ex-partner:

1 tries to limit your contact with family or friends;

2 puts you down or calls you names to make you feel bad;

3 is jealous and doesn't want you to talk to other men or women;

4 harms, or threatens to harm, someone close to you;

5 harms or threatens to harm your pet(s);

6 demands to know who you are with and where you are at all times;

7 damages or destroys your possessions or property. literature examining socio-demographic risk factors for CM and IPV [23, 43-47] as well as socio-demographic controls used in other studies investigating $\mathrm{CM}$ in relation to IPV in adulthood [5-10, 13-15]. The control variables used in this study include: current age (18-24, $25-39,40-54,55-69,70$ or older), born in Canada (yes/ no), Indigenous status (First Nations, Métis or Inuk (Inuit)/non-Indigenous), marital status (married, living common-law, widowed, divorced, separated, single/never married), household income (less than $\$ 20,000, \$ 20$, $000-\$ 39,000, \$ 40,000-\$ 59,000, \$ 60,000-\$ 79,000, \$ 80$, $000-\$ 99,000, \$ 100,000$ or more), highest level of education attained by respondent (less than high school graduation, high school diploma, postsecondary certificate/diploma, university degree), and highest level of education attained by respondent's mother and father (less than high school graduation, high school diploma, some postsecondary, postsecondary certificate/diploma, university degree).

\section{Analysis}

Frequency estimates were produced to describe the prevalence of CM and IPV among the study population. Associations between CM and IPV in adulthood were examined using cross-tabulations and logistic regression models that controlled for potential confounders. Two sets of analyses were conducted to address objectives 1 and 2; one based on binary (yes/no) CM variables, and the other to examine severity. The small proportion of respondents with missing data for the $\mathrm{CM}$ and/or IPV variables (Table 2) were excluded from the analyses.

All analyses were based on weighted data. Weights created by Statistics Canada ensured that the data were representative of the Canadian population in 2014. To account for the survey design effect of the GSS, standard errors, coefficients of variation, and 95\% confidence intervals were estimated using the bootstrap technique [38]. Differences between estimates were tested for statistical significance, which was established at the $p<0.05$ level. All analyses were conducted using SAS 9.4 (SAS Institute Inc.; Cary, North Carolina, USA).

Preliminary analyses considered CM in relation to the three types of IPV in adulthood: physical, sexual, and emotional. Sample size was not sufficient to examine associations with sexual IPV separately; therefore, sexual and physical IPV were combined. Owing to the overlap between physical/sexual and emotional IPV, we examined associations between $\mathrm{CM}$ and three outcomes: emotional IPV alone (no physical/sexual IPV); physical/sexual IPV alone (no emotional IPV); and both emotional IPV and physical/sexual IPV. Sample size was insufficient to determine associations between CM and physical/sexual IPV with no emotional IPV. When the outcomes were emotional IPV with no physical/sexual IPV or physical/sexual 
Table 2 Percentage experiencing intimate partner violence (IPV) in adulthood and childhood maltreatment (CM), by sex, household population aged 18 or older, currently living with a spouse/partner or who had contact with an ex-spouse/partner during last 5 years, Canada, 2014

\begin{tabular}{|c|c|c|c|c|c|c|}
\hline & \multicolumn{3}{|l|}{ Men } & \multicolumn{3}{|l|}{ Women } \\
\hline & Sample size & Weighted percent & $95 \% \mathrm{Cl}$ & Sample size & Weighted percent & $95 \% \mathrm{Cl}$ \\
\hline & \multicolumn{6}{|c|}{ IPV in adulthood } \\
\hline \multicolumn{7}{|l|}{ Any IPV } \\
\hline Yes & 1684 & 16.1 & $(15.1,17.1)$ & 1911 & $14.0^{*}$ & $(13.2,14.8)$ \\
\hline No & 8743 & 83.9 & $(82.9,84.9)$ & 9389 & 86.0 & $(85.2,86.8)$ \\
\hline Missing & 181 & & & 158 & & \\
\hline \multicolumn{7}{|l|}{ Emotional IPV } \\
\hline Yes & 1563 & 14.9 & $(13.9,15.8)$ & 1808 & $13.1^{*}$ & $(12.3,13.9)$ \\
\hline No & 8896 & 85.1 & $(84.2,86.1)$ & 9521 & 86.9 & $(86.1,87.7)$ \\
\hline Missing & 149 & & & 129 & & \\
\hline \multicolumn{7}{|l|}{ Physical IPV } \\
\hline Yes & 435 & 4.3 & $(3.7,4.9)$ & 572 & $3.5^{*}$ & $(3.1,3.9)$ \\
\hline No & 10,030 & 95.7 & $(95.1,96.3)$ & 10,755 & 96.5 & $(96.1,96.9)$ \\
\hline Missing & 143 & & & 131 & & \\
\hline \multicolumn{7}{|l|}{ Sexual IPV } \\
\hline Yes & 14 & $\mathrm{~F}$ & & 81 & $0.5^{*}$ & $(0.3,0.6)$ \\
\hline No & 10,456 & 99.9 & $(99.8,100)$ & 11,250 & 99.5 & $(99.4,99.7)$ \\
\hline Missing & 138 & & & 127 & & \\
\hline \multicolumn{7}{|l|}{ Physical or sexual IPV } \\
\hline Yes & 437 & 4.3 & $(3.7,4.9)$ & 582 & $3.6^{*}$ & $(3.2,4.0)$ \\
\hline No & 10,020 & 95.7 & $(95.1,96.3)$ & 10,741 & 96.4 & $(96.0,96.8)$ \\
\hline Missing & 151 & & & 135 & & \\
\hline \multicolumn{7}{|l|}{ Emotional IPV and/or physical/sexual IPV } \\
\hline Both emotional IPV and physical/sexual IPV & 316 & 3.2 & $(2.6,3.7)$ & 479 & 2.8 & $(2.4,3.2)$ \\
\hline Emotional IPV, no physical/sexual IPV & 1229 & 11.6 & $(10.8,12.5)$ & 1321 & $10.3^{*}$ & $(9.5,11.0)$ \\
\hline Physical/sexual IPV, no emotional IPV & 120 & 1.2 & $(0.9,1.5)$ & 102 & 0.8 & $(0.6,1.0)$ \\
\hline No emotional IPV and no physical/sexual IPV & 8743 & 84.0 & $(83.0,85.0)$ & 9389 & 86.1 & $(85.3,86.9)$ \\
\hline Missing & 200 & & & 167 & & \\
\hline
\end{tabular}

\section{Childhood maltreatment}

\section{Any $\mathrm{CM}^{\mathrm{a}}$}

Yes

No

Missing

CPA

Yes

No

Missing

CPA severity and frequency

Severe and frequent CPA

Severe CPA ( $\leq 10$ times)

CPA (excluding severe CPA)

No CPA

Missing

\section{7}

7.4

13.1

76.7
$(25.8,28.0) \quad 3047$

$(72.0,74.2) \quad 8120$

291

$(22.3,24.5) \quad 1771$

$(75.5,77.7) \quad 9431$

256
$(2.3,3.1) \quad 260$

$(6.8,8.1) \quad 508$

$(12.3,14.0) \quad 991$

$(75.7,77.8) \quad 9431$

268
$25.1^{*}$

74.9

(24.0, 26.2)

$(73.8,76.0)$

(13.7, 15.4)

$(84.6,86.3)$
$(1.6,2.3)$

$(3.6,4.6)$

$(7.7,9.1)$

$(84.7,86.4)$ 
Table 2 Percentage experiencing intimate partner violence (IPV) in adulthood and childhood maltreatment (CM), by sex, household population aged 18 or older, currently living with a spouse/partner or who had contact with an ex-spouse/partner during last 5 years, Canada, 2014 (Continued)

\begin{tabular}{|c|c|c|c|c|c|c|}
\hline & \multicolumn{3}{|l|}{ Men } & \multicolumn{3}{|l|}{ Women } \\
\hline & Sample size & Weighted percent & $95 \% \mathrm{Cl}$ & Sample size & Weighted percent & $95 \% \mathrm{Cl}$ \\
\hline \multicolumn{7}{|l|}{ CSA } \\
\hline Yes & 557 & 4.7 & $(4.2,5.2)$ & 1705 & $13.5^{*}$ & $(12.7,14.3)$ \\
\hline No & 9823 & 95.3 & $(94.8,95.8)$ & 9550 & 86.5 & $(85.7,87.3)$ \\
\hline Missing & 228 & & & 203 & & \\
\hline \multicolumn{7}{|l|}{ CSA severity and frequency } \\
\hline Severe and frequent ( $\geq 3$ times) CSA & 93 & 0.7 & $(0.5,0.9)$ & 406 & $3.2^{*}$ & $(2.7,3.6)$ \\
\hline Severe CSA ( $\leq 2$ times) & 180 & 1.6 & $(1.3,1.9)$ & 507 & $4.1^{*}$ & $(3.6,4.5)$ \\
\hline Sexual touching (excluding severe CSA) & 282 & 2.5 & $(2.1,2.9)$ & 786 & $6.2^{*}$ & $(5.7,6.8)$ \\
\hline No CSA & 9823 & 95.3 & $(94.8,95.8)$ & 9550 & 86.5 & $(85.7,87.3)$ \\
\hline Missing & 230 & & & 209 & & \\
\hline \multicolumn{7}{|l|}{ Childhood exposure to IPV } \\
\hline Yes & 624 & 5.4 & $(4.9,6.0)$ & 888 & $7.0^{*}$ & $(6.3,7.7)$ \\
\hline No & 9729 & 94.6 & $(94.0,95.1)$ & 10,377 & 93.0 & $(92.3,93.7)$ \\
\hline Missing & 255 & & & 193 & & \\
\hline \multicolumn{7}{|l|}{ Frequency of childhood exposure to IPV } \\
\hline More than 10 times & 276 & 2.2 & $(1.9,2.6)$ & 478 & $3.5^{*}$ & $(3.0,4.0)$ \\
\hline Three to 10 times & 348 & 3.2 & $(2.8,3.6)$ & 410 & 3.5 & $(3.0,4.0)$ \\
\hline Never, once or twice & 9729 & 94.6 & $(94.0,95.1)$ & 10,377 & 93.0 & $(92.3,93.7)$ \\
\hline Missing & 255 & & & 193 & & \\
\hline \multicolumn{7}{|l|}{ Co-occurrence of CM } \\
\hline No CM & 7218 & 73.6 & $(72.4,74.7)$ & 8120 & 75.4 & $(74.3,76.4)$ \\
\hline CPA only (no CSA/Childhood exposure to IPV) & 1780 & 17.0 & $(16.1,18.0)$ & 791 & $6.9^{*}$ & $(6.3,7.6)$ \\
\hline CSA only (no CPA/Childhood exposure to IPV) & 209 & 2.0 & $(1.6,2.3)$ & 889 & $7.3^{*}$ & $(6.6,7.9)$ \\
\hline Childhood exposure to IPV only (no CPA/CSA) & 137 & 1.3 & $(1.0,1.6)$ & 259 & $2.4^{*}$ & $(1.9,2.8)$ \\
\hline Two or 3 types of CM & 700 & 6.1 & $(5.6,6.7)$ & 1032 & $8.1^{*}$ & $(7.4,8.7)$ \\
\hline Missing & 564 & & & 367 & & \\
\hline
\end{tabular}

Source: Statistics Canada: 2014 General Social Survey: Victimization

CPA: childhood physical abuse; CSA: childhood sexual abuse

${ }^{a}$ CPA, CSA or childhood exposure to IPV

* Significantly different from men $(p<0.05)$

$\mathrm{F}$ too unreliable to be published

IPV and emotional IPV, associations with CM were similar. Therefore, only the results for any IPV (physical, sexual, or emotional) are presented.

To examine sex differences in associations between $\mathrm{CM}$ and IPV, logistic regression was used to test for interactions with sex and CM. A significant interaction indicates that the strength of the association between $\mathrm{CM}$ and IPV differs by sex (for example, if a statistically significant interaction greater than 1.0 is found between $\mathrm{CM}$ and IPV for being female, the association with IPV is stronger for women than for men). When significant interactions terms were found, we reported on relative risks based on rates since it is not appropriate to compare odds ratios across models.

\section{Results}

\section{Estimates of IPV}

Among people aged 18 years or older currently living with a spouse/partner or who had contact with an exspouse/partner in the last 5 years, a slightly higher percentage of men than women reported any IPV victimization (physical, sexual or emotional): $16.1 \%$ versus $14.0 \%$ (Table 2).

Men were more likely than women to report physical and emotional IPV, while women were more likely to report sexual IPV. Based on Statistics Canada guidelines, the sample size for men who reported sexual IPV was too small for the estimate to be published; therefore, the combined percentage reporting physical/sexual IPV is presented. 
The percentages of men and women reporting both emotional IPV and physical/sexual IPV were similar (3.2 and $2.8 \%$, respectively). Reporting physical/sexual IPV with no emotional IPV was rare for both sexes (1.2 and $0.8 \%$, respectively). Among the population who reported physical/sexual IPV, it was very common to also report emotional IPV; $72.7 \%$ among men and $77.4 \%$ among women (data not shown).

\section{Estimates of CM}

Men were slightly more likely than women to report any CM: $26.9 \%$ versus $25.1 \%$. A higher percentage of men than women reported CPA (23.4\% versus $14.6 \%)$, but women were more likely to report CSA (13.5\% versus $4.7 \%$ ) and childhood exposure to IPV (7.0\% versus $5.4 \%$ ). Similarly, men were more likely than women to report severe/frequent CPA, while women were more likely to report severe/frequent CSA and frequent childhood exposure to IPV. A higher percentage of women than men reported co-occurrence of two or more forms of CM (8.1\% versus $6.1 \%)$.

\section{Associations between CM and IPV}

For both sexes, those who had experienced any CM were more likely to report being victimized by IPV in adulthood (Table 3). Among men reporting any CM, 23.4\% reported IPV in adulthood, compared with $13.2 \%$ of those who did not experience CM; among women, the corresponding figures were 23.0 and $10.9 \%$. Men and women who had experienced each type of CM (CPA, CSA and childhood exposure to IPV) had higher rates of IPV than did those who had not.

The associations between the three individual types of CM and IPV in adulthood persisted when potential socio-demographic confounders were taken into account. For both sexes, the adjusted odds ratios for reporting IPV were significant for each type of CM. When we simultaneously controlled for the cooccurrence of CM, all three types remained statistically significant for both sexes, demonstrating that each type is independently associated with IPV in adulthood.

\section{Associations between severity of CM and IPV}

When severity/frequency of CM was considered, a doseresponse relationship between $\mathrm{CPA}$ and IPV in adulthood emerged for both sexes-as the frequency/severity of CPA increased, so did the likelihood of reporting IPV (Table 4). The highest IPV rates were among those who had experienced severe/frequent CPA (31.3\% for men and $31.8 \%$ for women), substantially exceeding the rates among those who had not experienced any CPA (13.8\% for men and $11.8 \%$ for women).

Among women, a dose-response relationship emerged between severity/frequency of CSA and IPV. By contrast, among men, there were no statistically significant differences by severity/frequency of CSA.

Also, for women, a dose-response relationship was observed between the frequency of childhood exposure to IPV and IPV in adulthood; this was not the case for men.

Women who had experienced two or more types of CM had a higher likelihood of reporting IPV in adulthood than did those who had experienced only one of the three types. However, among men, having experienced multiple types of CM was not associated with a higher rate of IPV; rates were similar among those who had experienced two or more types of CM and those who had experienced one type.

The bivariate associations between the severity/frequency $\mathrm{CM}$ variables and being victimized by IPV in adulthood persisted when controlling for potential socio-demographic confounders.

\section{Sex differences in associations between CM and IPV}

To examine sex differences, we combined the sexes, and using logistic regression, we tested for interactions between sex and CM in relation to reporting IPV in adulthood, while controlling for potential socio-demographic confounders. A significant sex interaction was observed for CPA-the association between CPA and IPV in adulthood was stronger for women than for men. Women who reported CPA were 2.2 times more likely to experience IPV in adulthood than were those who did not report CPA (25.9/11.8) (Table 3). For men, the disparity was smaller, with those reporting CPA being 1.7 times more likely to experience IPV in adulthood than were those who did not report CPA (23.3/13.8).

Significant sex interactions were also observed for CPA severity. Compared with men who reported no CPA, experiencing IPV in adulthood was 2.3 times higher (31.3/13.8) for those reporting severe and frequent CPA, 1.8 times higher (25.2/13.8) for severe CPA, and 1.5 times higher $(20.2 / 13.8)$ for CPA, excluding severe CPA (Table 4). Associations were stronger for women-compared with those reporting no CPA, experiencing IPV in adulthood was 2.7 higher for severe and frequent CPA, 2.6 for severe CPA, and 1.9 for CPA, excluding severe CPA.

Similarly, men who reported at least two types of CM were 2.0 times more likely to experience IPV in adulthood than those who reported no CM. For women, the gradient was steeper, with those reporting at least two types of CM being 2.9 times more likely to experience IPV in adulthood.

\section{Discussion}

This study, based on a large, representative sample of the Canadian population in 2014, found that CM is 
Table 3 Prevalence of and adjusted odds ratios for experiencing any intimate partner violence (IPV) in adulthood, by sex and childhood maltreatment (CM), household population aged 18 or older, currently living with a spouse/partner or who had contact with an ex-spouse/partner during last 5 years, Canada, 2014

\begin{tabular}{|c|c|c|c|c|}
\hline & \multicolumn{4}{|c|}{ Any IPV in adulthood } \\
\hline & $\%$ & $95 \% \mathrm{Cl}$ & Odds & $95 \% \mathrm{Cl}$ \\
\hline & Men & & & \\
\hline \multicolumn{5}{|l|}{ Any $\mathrm{CM}^{\mathrm{a}}$} \\
\hline Yes & $23.4^{*}$ & $(21.2,25.6)$ & $1.8 *$ & $(1.5,2.1)$ \\
\hline No (reference) & 13.2 & $(12.1,14.3)$ & 1.0 & $\ldots$ \\
\hline \multicolumn{5}{|l|}{ CPA } \\
\hline Yes & $23.3 *$ & $(21.0,25.6)$ & $1.7 *$ & $(1.4,2.0)$ \\
\hline No (reference) & 13.8 & $(12.7,14.9)$ & 1.0 & $\ldots$ \\
\hline \multicolumn{5}{|l|}{ CSA } \\
\hline Yes & $25.1 *$ & $(20.3,29.9)$ & $1.8 *$ & $(1.4,2.5)$ \\
\hline No (reference) & 15.5 & $(14.5,16.6)$ & 1.0 & $\ldots$ \\
\hline \multicolumn{5}{|l|}{ Childhood exposure to IPV } \\
\hline Yes & $27.7 *$ & $(23.0,32.4)$ & $2.0 *$ & $(1.5,2.6)$ \\
\hline No (reference) & 15.3 & $(14.3,16.3)$ & 1.0 & $\ldots$ \\
\hline \multicolumn{5}{|l|}{ Simultaneously controlling for other CM types } \\
\hline CPA (reference no CPA) & & & $1.5 *$ & $(1.3,1.8)$ \\
\hline CSA (reference no CSA) & & & $1.5 *$ & $(1.1,2.1)$ \\
\hline \multirow[t]{2}{*}{ Childhood exposure to IPV (reference no childhood exposure to IPV) } & & & $1.7 *$ & $(1.3,2.2)$ \\
\hline & Wome & & & \\
\hline \multicolumn{5}{|l|}{ Any $\mathrm{CM}^{\mathrm{a}}$} \\
\hline Yes & $23.0 *$ & $(21.1,25.0)$ & $2.1 *$ & $(1.8,2.5)$ \\
\hline No (reference) & 10.9 & $(10.0,11.8)$ & 1.0 & $\ldots$ \\
\hline \multicolumn{5}{|l|}{ CPA } \\
\hline Yes & $25.9 *$ & $(23.0,28.7)$ & $2.2 *$ & $(1.8,2.7)$ \\
\hline No (reference) & 11.8 & $(11.0,12.7)$ & 1.0 & $\ldots$ \\
\hline \multicolumn{5}{|l|}{ CSA } \\
\hline Yes & $24.8 *$ & $(22.1,27.4)$ & $2.0 *$ & $(1.7,2.5)$ \\
\hline No (reference) & 12.2 & $(11.3,13.1)$ & 1.0 & $\ldots$ \\
\hline \multicolumn{5}{|l|}{ Childhood exposure to IPV } \\
\hline Yes & $26.6 *$ & $(22.6,30.7)$ & $2.1 *$ & $(1.6,2.8)$ \\
\hline No (reference) & 13.0 & $(12.2,13.8)$ & 1.0 & $\ldots$ \\
\hline \multicolumn{5}{|l|}{ Simultaneously controlling for other CM types } \\
\hline CPA (reference no CPA) & & & $1.8 *$ & $(1.4,2.2)$ \\
\hline CSA (reference no CSA) & & & $1.6^{*}$ & $(1.3,1.9)$ \\
\hline Childhood exposure to IPV (reference no childhood exposure to IPV) & & & $1.5 *$ & $(1.2,2.0)$ \\
\hline
\end{tabular}

Source: Statistics Canada: 2014 General Social Survey: Victimization

CPA: childhood physical abuse; CSA: childhood sexual abuse

${ }^{a}$ CPA, CSA or childhood exposure to IPV

* Significantly different from reference $(p<0.05)$

Note: Odds are adjusted by age group, Canadian-born, Indigenous status, marital status, household income, highest level of education of respondent, and highest level of education of respondent's father and mother

... not applicable

associated with IPV in adulthood. For both sexes, CPA, CSA and childhood exposure to IPV were independently associated with subsequent IPV. Associations between
CPA and IPV were stronger for women than for men. Among women, a dose-response relationship emerged between each of the three types of CM and IPV in 
Shields et al. BMC Public Health $\quad$ (2020) 20:1673

Page 9 of 15

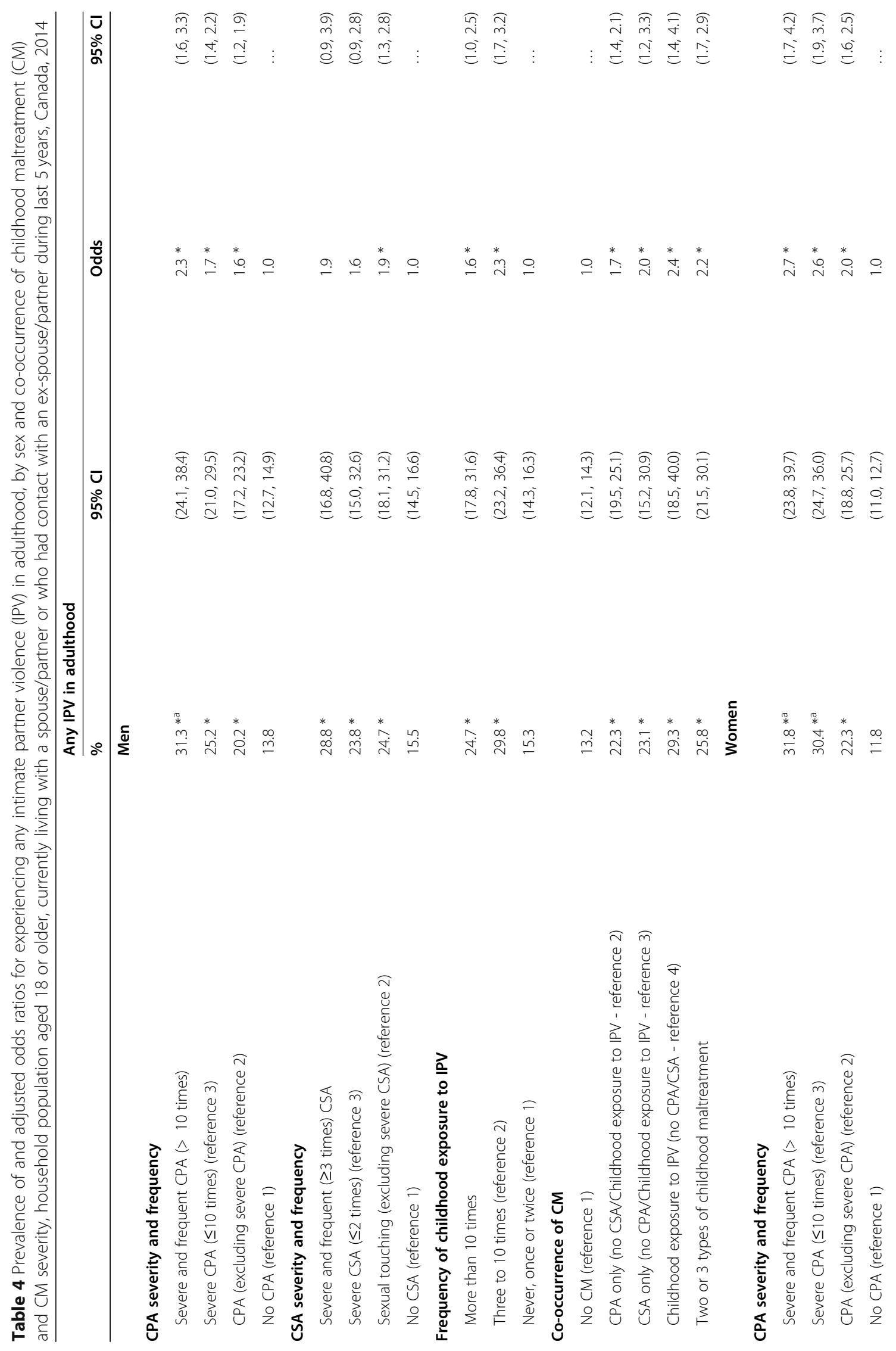


Shields et al. BMC Public Health $\quad$ (2020) 20:1673

Page 10 of 15

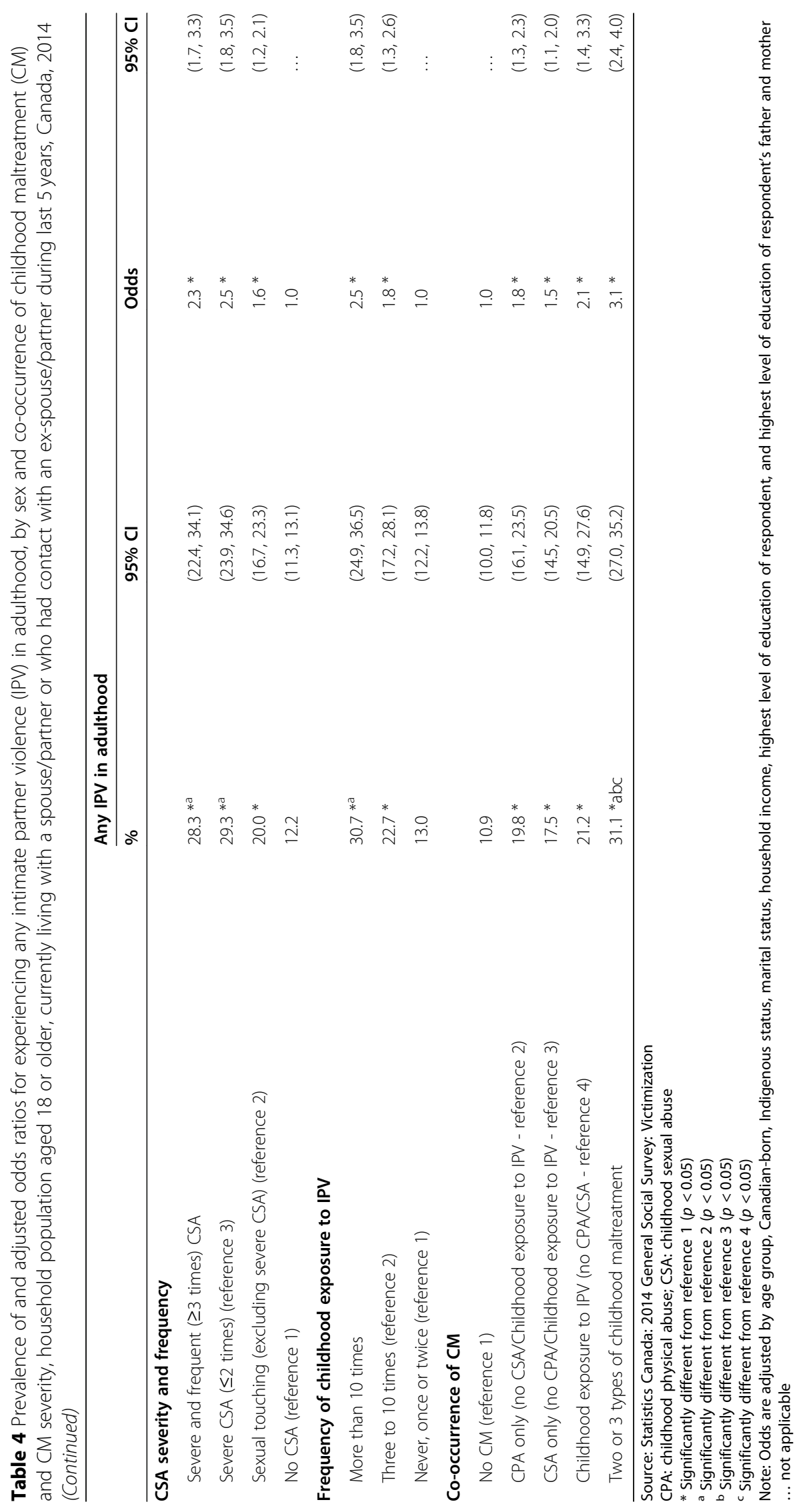


adulthood-increases in the severity and frequency of the $\mathrm{CM}$ were associated with increases in the likelihood of reporting IPV; among men, a dose-response relationship was observed only for CPA. For women, but not men, having experienced two or more types of $\mathrm{CM}$ was more strongly associated with IPV than was experiencing one type.

Consistent with results of a study based on data from a 2012 Canadian survey [43], the present analysis found that women were more likely than men to report CSA and childhood exposure to IPV, while men were more likely than women to report CPA.

The present study found that men were slightly more likely than women to report IPV in adulthood. Other studies have also found that women are equally, or somewhat less likely, than men to report IPV, particularly when IPV is broadly defined to include any type of hitting and/or emotional IPV $[48,49]$. However, it is important to note that women are at increased likelihood of experiencing severe/frequent IPV, as well as serious consequences, such as psychological harm, physical injuries and mortality [50-52].

Many other studies have found that IPV in adulthood is more common among people who have experienced CSA [5-18] and CPA [5-7, 9, 10, 12-22]. Fewer studies have examined IPV in relation to other types of CM, but associations have been found for childhood exposure to IPV [5, 13, 16-20, 23-25], neglect [5, 6, 14, 15, 20, 22], and childhood emotional abuse $[5,6,14,15,20]$. Nonetheless, results have been inconsistent, with some studies finding a null association between specific types of CM and IPV [5-7, 12-14, 19, 20, 22, 24, 26-29]. This likely reflects differences in the definitions of CM and IPV, the reference periods for CM and IPV, the control variables in the analyses (including simultaneously controlling for multiple types of $\mathrm{CM}$ ), the study population, and the sample size.

CM severity in relation to IPV in adulthood has been studied less frequently. It has been suggested that exposure to CM, regardless of severity, increases the risk of subsequent abuse [33]. Two meta-analyses of associations between CM and IPV published in 2019 (one based solely on men and one on both sexes) [30,31] reported weak but statistically significant associations. Failure to account for severity of the CM may have masked the full nature of the association. According to our analysis, severity was an important factor, especially for women.

Much of the research examining associations between CM and IPV has been based solely on samples of women; sex differences have rarely been examined. It has been suggested that the lack of studies on male IPV victimization reflects the more serious consequences experienced by females victimized by IPV [30]. Similar to our results for women, other studies revealed a dose-response relationship between the number of types of CM and IPV in adulthood [5, 9, $12,15,18-20,28,32]$. We found that associations between CPA and IPV were stronger among women, but the association was also significant among men. Additional work is needed using mixed gender samples in which multiple types of CM and IPV are considered. Most studies based on men have focused solely on IPV perpetration [30]. However, studies including males victimized by IPV are important to inform both the general population and health care professionals of the importance of recognizing that men also experience victimization and for the development of interventions aimed at reducing male IPV victimization [30].

The most common framework for interpreting IPV risk factors is the ecological model $[3,4]$. This model extends beyond individual characteristics to encompass family, community, and societal factors. It recognizes that individuals evolve within a set of nested environmental structures and attempts to identify mechanisms that contribute to vulnerability to repeated abuse. Exosystem and macro-system variables, such as a scarcity of resources, lack of social support, and cultural tendencies to blame the victim, may increase the likelihood that people who experienced CM will be exposed to IPV in adulthood, independent of their individual characteristics. For example, lack of access to affordable housing and well-paying jobs may increase the likelihood that individuals with histories of $\mathrm{CM}$ will enter and maintain intimate relationships with people who are violent toward them. $\mathrm{CM}$ is associated with numerous negative long-term economic outcomes including unemployment, low income, homelessness, and lack of job skills [44]. This is further exacerbated by experiences of adult IPV victimization which have been shown to inhibit job stability [53].

Another ecological consideration is that the abusive and violent behaviours towards children and partners may not be condemned universally. If people grow up and continue to live in a social milieu where violence is sometimes regarded as acceptable, exposure to frequent and severe violence in childhood may be a marker for exposure to violence in adulthood. This is consistent with the social learning theory model which contends that CM may serve as a model for future interpersonal relationships [54]. Children who experience abuse or have a caregiver who is abused may perceive violence as a normal part of a relationship. Initiatives such as the \#MeToo movement (https://metoomvmt.org/about/) may have a role in decreasing IPV. The movement may reduce the likelihood of accepting abuse of any kind in intimate relationships, regardless of past experiences of violence. Research based on Canadian administrative 
data found an increase in reporting sexual assaults to the police after the emergence of \#MeToo, particularly cases involving a known perpetrator [55].

The ecological model also incorporates the idea that the family environment in which the CM initially occurred may be associated with future abuse. A systematic review of risk and protective factors for revictimization after CSA found that the perception of parental care acted as a buffer, reducing the risk of revictimization [56].

A 2019 study [57] found that positive childhood experiences reduced the risk of poor mental health in adulthood, independent of childhood abuse and neglect and household dysfunction (such as parental substance abuse). The measures of positive childhood experiences included items such as participation in community traditions, a sense of belonging in high school, and social support from friends. These findings demonstrate the utility of the ecological model when investigating associations between $\mathrm{CM}$ and other negative outcomes in adulthood such as IPV.

\section{Strengths and limitations}

This study has notable strengths: it is based on a large, representative sample of the Canadian population; multiple behaviour-specific items were used to measure CM and IPV; and these measures have been shown to have greater validity and reliability than broad, subjectively defined items [41, 42, 58-60]. As a result, it was possible to examine CM severity in relation to IPV in adulthood and to test for sex differences in associations.

However, the analysis has limitations that should be considered when interpreting the findings:

- All information was based on retrospective selfreports. Recall bias may have influenced the observed associations between CM and IPV. People who experienced violence in adulthood may more readily recall $\mathrm{CM}$, which could have inflated associations. On the other hand, those who experienced CM may be less likely to report IPV in adulthood because of habituation to violence in general; this would weaken associations.

- Individuals who experienced CM and/or IPV may have been reluctant to disclose these experiences in a survey.

- The items used to measure IPV in adulthood were asked only of respondents with a current spouse or common-law partner and/or those who had contact with an ex-spouse/common-law partner in the past 5 years. IPV that occurred in dating relationships was excluded. Evidence suggests that the association between CM and IPV is stronger for dating couples than for married ones [31].
- The GSS questionnaire did not include measures of childhood emotional abuse and neglect, which have been shown to be associated with IPV $[5,6$, $14,15,20,22]$.

- In the regression models, it was not possible to control for some potentially important confounders (such as overall family dysfunction) due to unavailability in the GSS. It has been hypothesized that family dysfunction may be more strongly related to negative outcomes than is $\mathrm{CM}$, but some research indicates that each is independently related to dysfunction in adulthood [61]. Socioeconomic status during childhood was partially controlled by inclusion of highest level of education of the father and mother in the regression analyses; family income data would have offered a more complete control for childhood socioeconomic status.

- The coverage of the GSS excludes people who are homeless and those living in institutions-populations for which experiences of $\mathrm{CM}$ and IPV are more prevalent.

- The extent to which the low GSS response rate (52.9\% for the provinces; $58.7 \%$ for the territories) affects associations between CM and IPV is unknown. An analysis of data from Statistics Canada's Canadian Community Health Survey (an ongoing annual health survey) reported steady declines in response rates over time. The characteristics of respondents and non-respondents differed in ways that cannot be fully corrected via weighting [62]. Furthermore, vulnerable populations (for instance, lower socioeconomic status and poor health) $[62,63]$ are the least likely to respond to surveys.

- Previous studies have found that $\mathrm{CM}$ is associated with IPV perpetration, particularly among men [8, 30, 32, 64, 65], and reciprocal IPV [8, 32, 65]. However, the GSS did not include questions on IPV perpetration so it was not possible to examine $\mathrm{CM}$ in relation to IPV perpetration.

- It is possible that there are subpopulations for which the associations between CM and IPV in adulthood are stronger such as Indigenous peoples [23]. The child's relationship to the perpetrator may also be an important factor [5]; children who experience abuse from a parent or caregiver may be at a heighted risk of experiencing IPV compared with those whose relationship to the abuser was more distant. We did not have adequate sample to examine interactions with these variables.

Future research should examine other types of $\mathrm{CM}$ such as neglect and emotional maltreatment in relation to IPV in adulthood. A survey with a larger sample size 
would be instrumental in identifying subpopulations with elevated associations between CM and IPV who are particularly in need of early interventions. More research on the effectiveness of community-based interventions such as fostering a sense of belonging to school and community traditions is warranted [57].

\section{Conclusion}

Numerous studies have found that both CM and IPV are associated with an increased risk of a wide range of physical and mental health conditions [66-68]. The negative outcomes of physical IPV are immediate and apparent, including injury, physical disability, and in severe cases, mortality [66]. However, emotional IPV also has serious ramifications; emotional IPV is strongly related to numerous adverse conditions, including chronic disease and poor mental health [69]. The association between CM and IPV in adulthood merits attention because of cumulative effects-lifespan studies have shown that individuals who experience numerous incidents of abuse exhibit the highest levels of impairment [70, 71]. Costs to the health care system and the burden to individuals experiencing multiple incidents of abuse underscore the importance of intervention programs to eradicate CM and IPV. Interventions aimed at promoting healthy relationships and providing emotional support and coping mechanisms to children and families in abusive situations are key components to ending the cycle of violence and preventing IPV in adulthood [72].

\footnotetext{
Abbreviations

Cl: confidence interval; CPA: childhood physical abuse; CSA: childhood sexual abuse; GSS: General Social Survey; IPV: intimate partner violence
}

\section{Acknowledgements}

Not applicable.

\section{Authors' contributions}

$M S, L T, W H, A G$ and HM conceived and designed the study. MS analyzed the data. MS and LT drafted the manuscript. WH, AG, and HM commented on and critically revised the manuscript. All authors read and approved the final manuscript.

\section{Funding}

No funding was received to conduct this research. HM is supported by the Chedoke Health Chair in Child Psychiatry.

\section{Availability of data and materials}

The data are available for analysis from Statistics Canada. MS conducted the analyses as an employee of Statistics Canada, under a contact between the Public Health Agency of Canada and Statistics Canada.

\section{Ethics approval and consent to participate}

Data for the GSS were collected by Statistics Canada under the provisions of the Statistics Act. Before starting the survey, GSS respondents were informed that the information they provided would be used for statistical purposes, that their answers would be kept strictly confidential, and their participation in the survey was voluntary. This article is based on data from an existing file and thus the project did not undergo ethics review.

\section{Consent for publication}

Not applicable.

\section{Competing interests}

The authors declare they have no competing interests.

\section{Author details}

${ }^{1}$ Public Health Agency of Canada, 785 Carling Ave. 7th floor, Ottawa, ON K1A OK9, Canada. ${ }^{2}$ Department of Psychiatry \& Behavioural Neurosciences, McMaster University, 1280 Main Street West - MIP 201A, Hamilton, ON L8S 4K1, Canada. ${ }^{3}$ Department of Psychiatry \& Behavioural Neurosciences, and of Pediatrics, McMaster University, 1280 Main Street West - MIP 201A, Hamilton, ON L8S 4K1, Canada.

Received: 30 May 2020 Accepted: 15 October 2020

Published online: 09 November 2020

\section{References}

1. World Health Organization. Responding to intimate partner violence and sexual violence against women: WHO clinical and policy guidelines. Geneva: World Health Organization; 2013.

2. Krug EG, Mercy JA, Dahlberg LL, Zwi AB. The world report on violence and health. Lancet. 2002;360(9339):1083-8.

3. Grauerholz L. An ecological approach to understanding sexual revictimization: linking personal, interpersonal, and sociocultural factors and processes. Child Maltreat. 2000;5(1):5-17.

4. Messman-Moore TL, Long PJ. The role of childhood sexual abuse sequelae in the sexual revictimization of women: an empirical review and theoretical reformulation. Clin Psychol Rev. 2003;23(4):537-71.

5. Aakvaag HF, Thoresen S, Wentzel-Larsen T, Dyb G. Adult victimization in female survivors of childhood violence and abuse: the contribution of multiple types of violence. Violence Against Women. 2017;23(13):1601-19.

6. Abajobir AA, Kisely S, Williams GM, Clavarino AM, Najman JM. Substantiated childhood maltreatment and intimate partner violence victimization in young adulthood: a birth cohort study. J Youth Adolesc. 2017;46(1):165-79.

7. Afifi TO, MacMillan H, Cox BJ, Asmundson GJ, Stein MB, Sareen J. Mental health correlates of intimate partner violence in marital relationships in a nationally representative sample of males and females. J Interpers Violence. 2009;24(8):1398-417.

8. Afifi TO, Mota N, Sareen J, MacMillan HL. The relationships between harsh physical punishment and child maltreatment in childhood and intimate partner violence in adulthood. BMC Public Health. 2017;17(1):493.

9. Barrios YV, Gelaye B, Zhong Q, Nicolaidis C, Rondon MB, Garcia PJ, et al. Association of childhood physical and sexual abuse with intimate partner violence, poor general health and depressive symptoms among pregnant women. PLoS One. 2015;10(1):e0116609.

10. Coid J, Petruckevitch A, Feder G, Chung W, Richardson J, Moorey S. Relation between childhood sexual and physical abuse and risk of revictimisation in women: a cross-sectional survey. Lancet. 2001;358(9280):450-4.

11. Daigneault I, Hebert M, McDuff P. Men's and women's childhood sexual abuse and victimization in adult partner relationships: a study of risk factors. Child Abuse Negl. 2009;33(9):638-47.

12. Desai S, Arias I, Thompson MP, Basile KC. Childhood victimization and subsequent adult revictimization assessed in a nationally representative sample of women and men. Violence Vict. 2002;17(6):639-53.

13. Renner LM, Slack KS. Intimate partner violence and child maltreatment: understanding intra- and intergenerational connections. Child Abuse Negl. 2006;30(6):599-617.

14. Seedat S, Stein MB, Forde DR. Association between physical partner violence, posttraumatic stress, childhood trauma, and suicide attempts in a community sample of women. Violence Vict. 2005;20(1):87-98.

15. Strom IF, Kristian HO, Myhre MC, Wentzel-Larsen T, Thoresen S. The social context of violence: a study of repeated victimization in adolescents and young adults. J Interpers Violence. 2017;886260517696867.

16. Swartout KM, Cook SL, White JW. Trajectories of intimate partner violence victimization. West J Emerg Med. 2012;13(3):272-7.

17. Thompson RS, Bonomi AE, Anderson M, Reid RJ, Dimer JA, Carrell D, et al. Intimate partner violence: prevalence, types, and chronicity in adult women. Am J Prev Med. 2006;30(6):447-57.

18. Whitfield CL, Anda RF, Dube SR, Felitti VJ. Violent childhood experiences and the risk of intimate partner violence in adults: assessment in a large health maintenance organization. J Interpers Violence. 2003;18(2):166-85. 
19. Bensley L, Van EJ, Wynkoop SK. Childhood family violence history and women's risk for intimate partner violence and poor health. Am J Prev Med. 2003;25(1):38-44.

20. Brassard A, Tourigny M, Dugal C, Lussier Y, Sabourin S, Godbout N. Child maltreatment and polyvictimization as predictors of intimate partner violence in women from the general population of Quebec. Violence Against Women. 2019;1077801219857824.

21. Fry D, McCoy A, Swales D. The consequences of maltreatment on children's lives: a systematic review of data from the East Asia and Pacific region. Trauma Violence Abuse. 2012;13(4):209-33.

22. Murphy LM. Childhood and adolescent violent victimization and the risk of young adult intimate partner violence victimization. Violence Vict. 2011; 26(5):593-607.

23. Brownridge DA, Taillieu T, Afifi T, Chaan KL, Emery B, Lavoie J, et al. Child maltreatment and intimate partner violence among indigenous and nonindigenous Canadians. J Fam Viol. 2016;32(6):607-19.

24. Ehrensaft MK, Cohen P, Brown J, Smailes E, Chen H, Johnson JG. Intergenerational transmission of partner violence: a 20-year prospective study. J Consult Clin Psychol. 2003;71(4):741-53.

25. Miszkurka M, Steensma C, Phillips SP. Correlates of partner and family violence among older Canadians: a life-course approach. Health Promot Chronic Dis Prev Can. 2016;36(3):45-53.

26. Fang $X$, Corso PS. Child maltreatment, youth violence, and intimate partner violence: developmental relationships. Am J Prev Med. 2007;33(4):281-90.

27. Fergusson DM, Horwood LJ, Lynskey MT. Childhood sexual abuse, adolescent sexual behaviors and sexual revictimization. Child Abuse Negl. 1997;21(8):789-803.

28. Moeller TP, Bachmann GA, Moeller JR. The combined effects of physical, sexual, and emotional abuse during childhood: long-term health consequences for women. Child Abuse Negl. 1993;17(5):623-40.

29. Widom CS, Czaja S, Dutton MA. Child abuse and neglect and intimate partner violence victimization and perpetration: a prospective investigation. Child Abuse Negl. 2014;38(4):650-63.

30. Godbout N, Vaillancourt-Morel MP, Bigras N, Briere J, Hebert M, Runtz M, et al. Intimate partner violence in male survivors of child maltreatment: a meta-analysis. Trauma Violence Abuse. 2019:20(1):99-113.

31. Li S, Zhao F, Yu G. Childhood maltreatment and intimate partner violence victimization: a meta-analysis. Child Abuse Negl. 2019;88:212-24.

32. Miller E, Breslau J, Chung WJ, Green JG, McLaughlin KA, Kessler RC. Adverse childhood experiences and risk of physical violence in adolescent dating relationships. J Epidemiol Community Health. 2011; 65(11):1006-13.

33. Maker AH, Kemmelmeier M, Peterson C. Child sexual abuse, peer sexual abuse, and sexual assault in adulthood: a multi-risk model of revictimization. J Trauma Stress. 2001;14(2):351-68.

34. Casey EA, Nurius PS. Trauma exposure and sexual revictimization risk: comparisons across single, multiple incident, and multiple perpetrator victimizations. Violence Against Women. 2005;11(4):505-30.

35. Statistics Canada. General Social Survey 2009 - Cycle 23 - Victimization Main Survey - Questionnaire Package. https://www23.statcan.gc.ca/imdb/p3 Instr.pl?Function=getInstrumentList\&|tem_Id=54684\&UL=1V Accessed 15 Jan 20200.

36. Statistics Canada. General Social Survey 2014 - Cycle 28 - Victimization. https://www23.statcan.gc.ca/imdb/p3Instr.pl?Function= getInstrumentList\&ltem_Id=148640\&UL=1V Accessed 15 Jan 20200

37. Burczycka M, Conroy S. Family violence in Canada: A statistical profile, 2015. Canadian Centre for justice statistics profile series. Ottawa: Statistics Canada; 2017.

38. Statistics Canada. General Social Survey, 2014. Cycle 28: Canadians' safety and security: victimization. Microdata User Guide Statistics Canada; 2015

39. Shields ME, Hovdestad WE, Pelletier C, Dykxhoorn JL, O'Donnell SC, Tonmyr L. Childhood maltreatment as a risk factor for diabetes: findings from a population-based survey of Canadian adults. BMC Public Health. 2016;16(1): 879.

40. Walsh CA, MacMillan $\mathrm{HL}$, Trocme N, Jamieson E, Boyle $\mathrm{MH}$. Measurement of victimization in adolescence: development and validation of the childhood experiences of violence questionnaire. Child Abuse Negl. 2008;32(11):1037-57.

41. Straus MA. Measuring intrafamily conflict and violence: the conflict tactics (CTS) scales. J Marriage Fam. 1979;41(1):75-88.
42. Straus MA, Hamby SL, Boney-McCoy S, Sugarman DB. The revised conflict tactics scales (CTS2): development and preliminary psychometric data. J Fam Issues. 1996;17:283-316.

43. Afifi TO, MacMillan HL, Boyle M, Taillieu T, Cheung K, Sareen J. Child abuse and mental disorders in Canada. CMAJ. 2014;186(9):E324-32.

44. Bunting L, Davidson G, McCartan C, Hanratty J, Bywaters P, Mason W, et al. The association between child maltreatment and adult poverty - a systematic review of longitudinal research. Child Abuse Negl. 2018;77:121-33.

45. Capaldi DM, Knoble NB, Shortt JW, Kim HK. A systematic review of risk factors for intimate partner violence. Partn Abus. 2012;3(2):231-80.

46. Drake B, Pandey S. Understanding the relationship between neighborhood poverty and specific types of child maltreatment. Child Abuse Negl. 1996; 20(11):1003-18.

47. Lefebvre R, Fallon B, Van Wert M, Filippelli J. Examining the Relationship between Economic Hardship and Child Maltreatment Using Data from the Ontario Incidence Study of Reported Child Abuse and Neglect-2013 (OIS2013). Behav Sci (Basel). 2017;7(1):6. https://doi.org/10.3390/bs7010006.

48. Archer J. Sex differences in aggression between heterosexual partners: a meta-analytic review. Psychol Bull. 2000;126(5):651-80.

49. Esquivel-Santovena E, Lambert TL, Hamel J. Partner abuse worldwide. Partn Abus. 2013:4(1):6-75.

50. Canadian Centre for Justice Statistics. Family violence in Canada: A statistical profile, 2014. Canadian Centre for justice statistics profile series. Ottawa: Statistics Canada; 2016

51. Stockl H, Devries K, Rotstein A, Abrahams N, Campbell J, Watts C, et al. The global prevalence of intimate partner homicide: a systematic review. Lancet. 2013;382(9895):859-65.

52. Yakubovich AR, Heron J, Feder G, Fraser A, Humphreys DK. Intimate partner violence victimisation in early adulthood: psychometric properties of a new measure and gender differences in the Avon longitudinal study of parents and children. BMJ Open. 2019;9(3):e025621.

53. Adams AE, Tolman RM, Bybee D, Sullivan CM, Kennedy AC. The impact of intimate partner violence on low-income women's economic well-being: the mediating role of job stability. Violence Against Women. 2012;18(12): 1345-67.

54. Messman TL, Long PJ. Child sexual abuse and its relationship to revictimization in adult women: a review. Clin Psychol Rev. 1996;16(5):397-420.

55. Rotenberg C, Cotter A. Police-reported sexual assaults in Canada before and after \#MeToo, 2016 and 2017. Canadian Centre for justice statistics profile series. Ottawa: Statistics Canada; 2018.

56. Scoglio AAJ, Kraus SW, Saczynski J, Jooma S, Molnar BE. Systematic review of risk and protective factors for revictimization after child sexual abuse. Trauma Violence Abuse. 2019;1524838018823274.

57. Bethell C, Jones J, Gombojav N, Linkenbach J, Sege R. Positive childhood experiences and adult mental and relational health in a statewide sample: associations across adverse childhood experiences levels. JAMA Pediatr. 2019. https://doi.org/10.1001/jamapediatrics.2019.3007. [published online September 9, 2019].

58. Fisher HL, Craig TK, Fearon P, Morgan K, Dazzan P, Lappin J, et al. Reliability and comparability of psychosis patients' retrospective reports of childhood abuse. Schizophr Bull. 2011:37(3):546-53.

59. Hardt J, Rutter M. Validity of adult retrospective reports of adverse childhood experiences: review of the evidence. J Child Psychol Psychiatry. 2004:45(2):260-73.

60. Thombs BD, Bernstein DP, Ziegelstein RC, Scher CD, Forde DR, Walker EA et al. An evaluation of screening questions for childhood abuse in 2 community samples: implications for clinical practice. Arch Intern Med. 2006;166(18):2020-6.

61. Jankowski MK, Leitenberg H, Henning K, Coffey P. Parental caring as a possible buffer against sexual revictimization in young adult survivors of child sexual abuse. J Trauma Stress. 2002;15(3):235-44.

62. Baribeau B. Could nonresponse be biasing trends of health estimates? Surv Methodol. 2014:4285-93.

63. Knoll M, Soller L, Ben-Shoshan M, Harrington D, Fragapane J, Joseph L, et al. The use of incentives in vulnerable populations for a telephone survey: a randomized controlled trial. BMC Res Notes. 2012;5:572.

64. Kimber M, Adham S, Gill S, McTavish J, MacMillan HL. The association between child exposure to intimate partner violence (IPV) and perpetration of IPV in adulthood-a systematic review. Child Abuse Negl. 2018;76:273-86. 
65. McKinney CM, Caetano R, Ramisetty-Mikler S, Nelson S. Childhood family violence and perpetration and victimization of intimate partner violence: findings from a national population-based study of couples. Ann Epidemiol. 2009:19(1):25-32.

66. Breiding MJ, Chen J, Black MC. Intimate partner violence in the United States - 2010. Atlanta: National Center for Injury Prevention and Control, Centers for Disease and Prevention; 2014

67. Maniglio R. The impact of child sexual abuse on health: a systematic review of reviews. Clin Psychol Rev. 2009;29(7):647-57.

68. Norman RE, Byambaa M, De R, Butchart A, Scott J, Vos T. The long-term health consequences of child physical abuse, emotional abuse, and neglect: a systematic review and meta-analysis. PLoS Med. 2012;9(11):e1001349.

69. Coker AL, Davis KE, Arias I, Desai S, Sanderson M, Brandt HM, et al. Physical and mental health effects of intimate partner violence for men and women. Am J Prev Med. 2002;23(4):260-8.

70. Follette VM, Polusny MA, Bechtle AE, Naugle AE. Cumulative trauma: the impact of child sexual abuse, adult sexual assault, and spouse abuse. J Trauma Stress. 1996;9(1):25-35.

71. Scott-Storey K. Cumulative abuse: do things add up? An evaluation of the conceptualization, operationalization, and methodological approaches in the study of the phenomenon of cumulative abuse. Trauma Violence Abuse. 2011;12(3):135-50.

72. Kimerling R, Alvarez J, Pavao J, Kaminski A, Baumrind N. Epidemiology and consequences of women's revictimization. Womens Health Issues. 2007; 17(2):101-6.

\section{Publisher's Note}

Springer Nature remains neutral with regard to jurisdictional claims in published maps and institutional affiliations.

Ready to submit your research? Choose BMC and benefit from:

- fast, convenient online submission

- thorough peer review by experienced researchers in your field

- rapid publication on acceptance

- support for research data, including large and complex data types

- gold Open Access which fosters wider collaboration and increased citations

- maximum visibility for your research: over $100 \mathrm{M}$ website views per year

At BMC, research is always in progress.

Learn more biomedcentral.com/submissions 